\title{
ENVIRONMENTAL RISK EVALUATION CRITERIA ${ }^{1}$
}

\author{
Harilaos N. Psaraftis \\ Laboratory for Maritime Transport \\ School of Naval Architecture and Marine Engineering \\ National Technical University of Athens \\ Greece \\ hnpsar@mail.ntua.gr \\ www.martrans.org
}

21 April 2008

\begin{abstract}
This paper describes an approach to incorporating environmental risk evaluation criteria within IMO's guidelines for Formal Safety Assessment (FSA). Such criteria are currently absent from FSA, and the discussion to include them has just started. Said criteria are relevant for evaluating on a cost-benefit basis Risk Control Options (RCOs) for reducing oil spill pollution risk. Oil pollution may come from any ship, including bunker spills from non-tank vessels. RCOs are not necessarily ship-based, and may include vessel traffic management information systems (VTMIS) and other options. The proposed approach may be useful in extending FSA to cover environmental risk evaluation criteria and combines such criteria with criteria already in use in FSA. It can also readily be extended to environmental consequences other than oil pollution.
\end{abstract}

Key words: Formal Safety Assessment, Environmental Risk Evaluation Criteria, Oil Pollution.

\section{Introduction}

At its broadest interpretation, an analysis of environmental risk in maritime transport certainly should not be confined to oil pollution, let alone pollution from oil tankers. In fact, the spectrum of the potential environmental consequences of a maritime accident is very broad, encompassing not only spills of cargo carried by oil tankers, but, among others, bunker spills from any ship, shipbuilding and ship recycling residues, ballast water, coatings, garbage, sewage, gas emissions, noise, radioactive and other hazardous materials, bio-fouling, chemicals, other dangerous cargoes, and others.

Thus far, work on Formal Safety Assessment (FSA) has limited the quantification of accident consequences only to possible fatalities (and indirectly also to injuries). No explicit environmental criteria are thus far included in the FSA Guidelines ${ }^{2}$. At the $56^{\text {th }}$ session of the Marine Environment Protection Committee (MEPC 56), it was noted that the one matter that needed consideration within the context of the FSA Guidelines relevant to the work of the MEPC was the draft "Environmental Risk

\footnotetext{
${ }^{1}$ Paper presented at the Second International Workshop on Risk-Based Approaches to the Maritime Industry, organized by the Ship Stability Research Centre, Universities of Glasgow and Strathclyde, Glasgow, UK, May 5-6, 2008.

${ }^{2}$ See IMO document MSC/Circ.1023 -MEPC/Circ.392, as consolidated in MSC 83/INF.2.
} 
Evaluation Criteria." In fact, already MEPC 55 had considered the draft criteria set out in IMO document MEPC 55/18 $8^{3}$ (Annex 3) and agreed that said criteria still needed in-depth consideration from the marine environment protection perspective. Subsequently, members were invited to give their views on the draft Environmental Risk Evaluation Criteria for consideration by MEPC 56.

The purpose of this paper is to describe an approach to incorporating environmental risk evaluation criteria within IMO's guidelines for Formal Safety Assessment (FSA). The proposed approach may be useful in extending FSA to cover environmental risk evaluation criteria and combines such criteria with criteria already in use in FSA. It can also readily be extended to environmental consequences other than oil pollution.

The rest of this paper is organized as follows. Section 2 reports on the discussion of this issue at the IMO. Section 3 talks about RCOs for reducing the risk of oil pollution. Section 4 proposes a method to assess these RCOs on a cost-benefit basis. Section 5 combines environmental risk and fatality risk. Section 6 extends this approach to other environmental criteria and Section 7 presents the conclusions. Annex A elaborates on the proposed approach from a methodological viewpoint.

\section{The discussion at the IMO}

A major topic in Annex 3 of doc. MEPC 55/18 and also in a report by EU research project SAFEDOR (Skjong et al, 2005) was the definition and analysis of risk evaluation criteria for accidental releases to the environment, and specifically for releases of oil. To that effect, the criterion of CATS (for "Cost to Avert one Tonne of Spilled oil") was defined as an environmental criterion equivalent to CAF, "Cost to Avert a Fatality". The latter criterion is widely used in FSA studies in which risk to human life is assessed and RCOs to reduce such risk are contemplated. According to the CATS criterion, a specific RCO for reducing environmental risk should be recommended for adoption if the value of CATS associated with it is below a specified threshold, otherwise that particular RCO should not be recommended. The equivalent threshold for the CAF analysis is $\$ 3$ million (doc. MSC 78/19/2).

In the SAFEDOR report, a threshold value in the neighborhood of $\$ 60,000$ per tonne of spilled oil was postulated for CATS, based on a series of modelling and other assumptions. The question whether the above value or another value is an appropriate one for use in IMO rule making or for other purposes is perhaps the most basic to be asked. But in our opinion it sidesteps a more general question, whether the CATS criterion in and of itself, that is, formulating an environmental index of costs averted on a per tonne of spill basis, is appropriate.

In fact, there is ample reference in the literature (see for instance Etkin (1999), among others, and even in Annex 3 of MEPC 55/18 itself) that the cost of oil spills on a dollar per tonne basis depends on a variety of parameters and has a broad variance. This is in agreement with doc. MSC 81/6/3 (submitted by Japan), which included, among others, statements such as "as mentioned above the quantity of oil outflow is not a good measure of the impact of the spill, since it does not have a linear

\footnotetext{
${ }^{3}$ We use the standard notational scheme of IMO documentation throughout this paper. Document MEPC $x / y / z$ means a document presented at the $x^{\text {th }}$ session of the MEPC, agenda item $y$, document number z. A similar notation holds for MSC (Maritime Safety Committee) documents.
} 
relationship with the risks to people and the environment. By concentrating on the quantity of the oil spilled the real risks are not being investigated." (from ISSC 2000, Annex of MSC 81/6/3, page 16).

According to the International Tanker Owners Pollution Federation- ITOPF (White and Molloy, 2003), factors that determine the clean-up cost of spills include (a) type of oil, (b) amount of oil spilled and rate of spillage, (c) physical, biological and economic characteristics of spill location, (d) weather and sea conditions, (e) time of the year and (f) effectiveness of clean-up. And in general, costs involved in oil spill incidents include (i) clean-up costs, (ii) indemnification of the owner and (iii) compensation costs to third-parties.

Therefore the point of primary importance that triggered the debate at the IMO was the adequacy or inadequacy of using any single dollar per tonne figure as an environmental criterion. Various spill cost data over the years suggested the following average cleanup costs worldwide (\$/tonne, 1999 dollars): 6.09 (Mozambique), 438.68 (Spain), 3,082.80 (UK), 25,614 (USA) and even the extreme value of 76,589 for the region of Malaysia (Etkin, 2000). The Exxon Valdez 37,000-tonne oil spill had a cleanup cost of $\$ 107,000 /$ tonne (2007 dollars), whereas the cleanup cost of the Braer 85,000 -tonne oil spill was as low as $\$ 6 /$ tonne $^{4}$. At least all of the above testify to the broad variation of values on a per tonne basis, which makes the use of any single dollar per tonne figure questionable (see also Kontovas and Psaraftis (2006)).

Anyway, MEPC 56 considered Greece's submission (doc. MEPC 56/18/1) which drew attention to these and other related issues, and noting that further work, including more research, was needed on the subject, agreed to establish a correspondence group (CG), under the co-ordination of Greece, in order to review the draft Environmental Risk Acceptance Criteria in FSA, and submit a written report to MEPC 57. The author of this paper was assigned the task to coordinate the CG.

After several months of deliberations, this report was submitted in December 2007 (doc. MEPC 57/17) and presented at MEPC 57 in April 2008 ${ }^{5}$. The report went at length on recording the positions and work of the CG members on this subject and recommending what to do next. Below is a very brief summary.

For starters, the terms of reference of the CG did not explicitly rule out a broad interpretation of the term "environmental risk acceptance criteria", or even of the term "oil pollution". However, the reference to annex 3 of MEPC 55/18 and to MEPC $56 / 18 / 1$, which essentially dealt only with oil pollution, implicitly limited the scope of the analysis of the CG. It is important to point out however, that the analysis was not confined to cargo spills from oil tankers, but included oil pollution from any ship (bunker spills definitely included).

Next, looking at Step 1 of FSA (Hazid), the exchange within the CG focused on what might be a proper environmental risk index or environmental risk matrix. In the FSA guidelines, the Risk Index (RI) is defined as the sum of the Frequency Index (FI),

\footnotetext{
${ }^{4}$ See Intertanko's contribution to doc. MEPC 57/17 for more details.

${ }^{5}$ The whole report can be found at: http://www.martrans.org/documents/2008/sft/mepc57-17.pdf
} 
expressed in number of accidents over ship-years, and the Severity Index (SI), expressed in terms of equivalent fatalities.

In order to extend this concept to environmental analysis, few or no changes in the definition of the Frequency Index (FI) are necessary, and in fact none of the CG members presented this is an issue. By contrast, much exchange took place regarding an appropriate definition of the Severity Index (SI). Some CG members pointed out that there may not be a single variable that can capture all environmental consequences. Some CG members debated whether recovery time, or (alternatively) oil spill volume is more appropriate as a consequence criterion, and there was a split of opinion on that. One member argued that no right or wrong risk matrix exists. Another member defined a severity index based on the economic consequences of environmental damages.

Perhaps the most lengthy exchange of views took place on the criterion to be used in Step 4 of the FSA (Cost- Benefit Assessment). The main thrust of Greece's position in doc. MEPC 56/18/1, pointing out the deficiencies of basing cost calculations on spill volume, was by and large supported by various arguments by the United States, Intertanko, the United Kingdom, and to some extent ITOPF. Intertanko presented an elaborate analysis on the components of the cost of oil pollution, and so did the United Kingdom. The United States stated that it had tried using a generic cost equivalent value for a barrel of oil or substance spilled, not spilled, or recovered, but no longer uses it due to regional differences and dependence on other attributes of casualty events. At the other side of the argument, Germany and Norway supported the CATS concept, as proposed by project SAFEDOR, and already alluded to in MEPC 55/18. ITOPF argued on the deficiencies of CATS, but also indicated that an index similar to CATS in terms of simplicity should be devised, and an appropriate value should be decided.

CG members not in favor of CATS did not propose an immediate alternative for it, noting that this could be the subject for further research, discussion and debate. Some members presented various ideas on the general approach (see doc. MEPC 57/17 for details), but no detailed proposal for an alternative criterion was put on the table.

The divergence of views on some important facets of the problem confirmed that the topic is of non-trivial complexity and perhaps even cannot be viewed as a simple extension of FSA. In view of the issues still left open after the correspondence group's deliberations, MEPC 57 renewed the terms of reference of the CG until MEPC 58 (see doc. MEPC 57/WP.10, section 17).

To sum up, the issues that are currently open and merit discussion are the following:

1) the issue of what is an appropriate severity index

2) the issue of what (if any) is a good alternative to CATS

3) the slope of F-N curves, the ALARP region and related matters.

As mentioned earlier, the main purpose of this paper is to address issue 2. It is not the scope of this paper to deal with either the severity matrix (or SI index), or the F-N curves. These are issues that are still open for discussion, but to some extent can be settled easily after issue 2, which is perhaps the most difficult issue, is settled. Clearly 
the issue of coming up with a scheme that can achieve a proper decision-making quality in FSA's cost-benefit step is the most important term of reference of the CG after MEPC 57. To that end, a scheme for assessing the cost-effectiveness of specific RCOs for reducing the risk of oil spill pollution is proposed herein. The scheme concerns mainly Steps 3 and 4 of the FSA methodology and is described next.

\section{RCOs for Reducing the Risk of Oil Spill Pollution}

It should be first mentioned that any RCO that reduces pollution risk may also, in general, reduce the risk of fatalities, of injuries, and maybe also the risk of damage or of loss of the ship and/or cargo. Incidents that lead to fatalities will not necessarily also lead to oil pollution, or vice versa. However, a specific methodology already exists in FSA for looking at a subset of these attributes (fatalities and injuries only). But attention should be made when combining the economic benefits of fatality risk reduction to those due to environmental risk reduction (more of this in Section 5). Quantification of risk reduction as regards damage or loss to ship and/or cargo has not been dealt with thus far in Step 4 of the FSA, and will not be dealt with here either.

Before we speak about possible RCOs, let us assume two scenarios: (a) the status quo, and (b) a scenario in which a specific RCO is applied to waterborne transport on a global basis. The purpose of this RCO is to reduce the risk of oil pollution, and this can be done by either reducing the probability of oil pollution or mitigating its consequences, or both. We need a way to decide whether or not this RCO is costeffective and hence should be recommended for adoption.

Focusing only on oil spill pollution risk, it comes as no surprise to see that there are a significant number of uncertainties in trying to estimate that risk, existing and future. Parameters such as time of spill, location of spill, volume of spill, type of oil spilled and others are not known in advance, but still may have significant implications on the anticipated total cost of oil pollution. In addition, significant difficulties may arise in terms of quantifying the economic consequences of oil pollution.

Starting with the status quo, let us define E(TOT) as the expected annual total cost of all spills worldwide. This cost basically consists of two components:

(a) The expected annual total damage cost of these spills, damage taking into account economic consequences to the shipowner, the cargo owner, fisheries, tourism, other industries that may be impacted negatively by the spill, and quantifiable damages to the environment, and

(b) The expected annual total cleanup cost of these spills, either at sea or when they hit the shoreline. This cost depends on the response level and response tactics, which here we assume to be a constant. Addressing oil spill response alternatives is outside the scope of this work.

Details on a proposed analytical method for calculating E(TOT) are presented in Annex A. For the moment, let us assume that this cost is known and that we would like it to be as low as possible. To do so, we contemplate ways to reduce it. 
To reduce this cost, we introduce a specific risk control option (RCO), to be applied either globally (to all ships) or locally (to all ships of a certain category, or to a certain geographical area). The total cost of applying this RCO is $\Delta \mathrm{K}$, assumed to be known ${ }^{6}$. $\triangle \mathrm{K}$ is a function of what is the RCO and how the RCO is applied: to all ships? to all geographical areas? Etc.

Typical examples of RCOs include:

- Tanker double sides

- Tanker double bottoms

- Smaller tanks

- Twin screws (for tankers)

- Inert gas in ballast tanks

- More steel

- Fuel tanks not close to ship hull

- ECDIS

- VTMIS

- Coulombi egg/ passive vacuum

- A specific design that limits discharge once it happens

- (perhaps theoretically?) rescinding double bottoms!

- Etc

Note that some of the RCOs may not be ship-related, eg, a more advanced VTMIS system that reduces the risk of collision. Some other RCOs are ship-related.

Effects of an RCO may generally include the following:

1) The spill frequency may change because of it (presumably it will be reduced).

2) The probability distribution of the spill volume may change (presumably less oil is likely to be spilled because of the RCO, and the expected spill volume will be reduced).

So the new situation, with the specific RCO under consideration implemented, and for the specific way that this is carried out, will achieve a different (presumably lower) expected annual total cost of all spills worldwide, $\mathrm{E}_{\mathrm{RCO}}(\mathrm{TOT})$. As before, this cost basically consists of two components:

(a) The expected annual total damage cost of these spills, and

(b) The expected annual total cleanup cost of these spills, either at sea or when they hit the shoreline.

As before, the analytical method for calculating $\mathrm{E}_{\mathrm{RCO}}$ (TOT) is presented in Annex A (it is very similar to the method for calculating $\mathrm{E}(\mathrm{TOT})$ ). For the moment, let us assume that this cost can be computed.

\footnotetext{
${ }^{6}$ For comparison purposes, $\Delta \mathrm{K}$ is assumed to be expressed as an equivalent annualized value. This means that if the cost of the RCO involves a lump sum investment, it should be converted to an equivalent annual basis. Such conversion is straightforward.
} 


\section{Cost benefit assessment}

With the above in mind, once we know $\mathrm{E}$ (TOT) and $\mathrm{E}_{\mathrm{RCO}}$ (TOT), we can calculate the expected cost differential between the status quo and the situation in which the RCO under consideration is applied.

$\Delta \mathrm{E}(\mathrm{TOT})=\mathrm{E}(\mathrm{TOT})-\mathrm{E}_{\mathrm{RCO}}(\mathrm{TOT})$, total expected cost averted due to the global application of the RCO.

For Step 4 of the FSA we can then say that

- The specific RCO under consideration is cost-effective globally if its total cost $\Delta \mathrm{K}<\Delta \mathrm{E}$ (TOT), otherwise it is not.

- Among alternative RCOs that pass this criterion, the one that achieves the highest positive difference $\{\Delta \mathrm{E}(\mathrm{TOT})-\Delta \mathrm{K}\}$ is preferable.

Note that we are talking about the RCO that achieves a maximum positive difference $\Delta \mathrm{E}(\mathrm{TOT})-\Delta \mathrm{K}$, not the one that maximizes the ratio of $\Delta \mathrm{E}(\mathrm{TOT}) / \Delta \mathrm{K}$. These are not the same, as shown in the example below.

Example: Assume three hypothetical RCOs, as follows (cost figures are in US \$ billion/year)

\begin{tabular}{|l|l|l|l|l|}
\hline $\mathbf{R C O}$ & $\mathbf{\Delta K}$ & $\mathbf{\Delta E}(\mathbf{T O T})$ & $\mathbf{\Delta E}(\mathbf{T O T})-\mathbf{\Delta K}$ & $\mathbf{\Delta E}(\mathbf{T O T}) / \mathbf{\Delta K}$ \\
\hline $\mathrm{RCO} 1$ & 2 & 5 & 3 & 2.5 \\
\hline $\mathrm{RCO} 2$ & 3 & 6.5 & 3.5 & 2.17 \\
\hline RCO3 & 4 & 8 & 4 & 2 \\
\hline
\end{tabular}

Among these three RCOs, $\mathrm{RCO} 3$ is preferable since it achieves the highest (positive) difference of $\Delta \mathrm{E}(\mathrm{TOT})-\Delta \mathrm{K}$, even though the other two RCOs achieve a higher $\Delta \mathrm{E}(\mathrm{TOT}) / \Delta \mathrm{K}$ ratio. If the maximum ratio $\mathrm{RCO}$ is chosen $(\mathrm{RCO} 1)$, it would lead to one billion dollars per year less expected benefits than those under RCO3. As a general rule, one should pay attention to ratio tests, since they ignore scale.

A question that might arise is, since RCOs that reduce pollution risk may also reduce the risk of fatalities, how can this be incorporated into the analysis?

\section{Combining environmental risk and fatality risk}

In FSA, the criterion for quantifying the impact of fatality reduction due to a certain RCO uses the concept of CAF (Cost to Avert a Fatality) and is roughly expressed as follows:

- If $\mathrm{CAF}=\Delta \mathrm{C} / \Delta \mathrm{R}<\mathrm{VHL}$, then $\mathrm{RCO}$ is cost-effective, otherwise not.

- Among alternatives that pass this test, choose the one with the minimum CAF.

In the above formula, $\Delta \mathrm{C}$ is the expected cost of the $\mathrm{RCO}, \Delta \mathrm{R}$ is the expect reduction of fatalities due to the RCO, and VHL is an estimate of the value of human life (the 
value currently used in FSA studies is 3 million US dollars per person) ${ }^{7}$. Both $\Delta \mathrm{C}$ and $\Delta \mathrm{R}$ are assumed to be expressed on an annual basis.

It is possible to combine fatality and environmental criteria as follows:

- The specific RCO under consideration is cost-effective globally if its cost $\Delta \mathrm{K}$ $<\Delta \mathrm{E}(\mathrm{TOT})+\mathrm{VHL}^{*} \Delta \mathrm{R}$, otherwise it is not ${ }^{8}$.

- Among alternative RCOs that pass this test, choose the one that achieves the highest positive difference $\left\{\Delta \mathrm{E}(\mathrm{TOT})+\mathrm{VHL}^{*} \Delta \mathrm{R}-\Delta \mathrm{K}\right\}$.

Again note the non-use of a ratio test in this step, which avoids possible pitfalls ${ }^{9}$.

The above is a general yet simple framework, which can be implemented as long as the data necessary for conducting the necessary calculations to compute the above variables is available. Such data is available, and it is speculated that even preliminary estimates may be developed before the full analysis is implemented.

Annex A provides more details on the approach, along with its relationship to the approach of CATS.

\section{Extensions to other environmental consequences}

The approach above can be readily extended if environmental consequences other than oil pollution are also examined. This is not currently under the terms of reference of this CG, but one can predict that eventually it will be the subject of analysis in FSA, and probably sooner rather than later. These other environmental consequences may include shipbuilding and ship recycling residues, ballast water, coatings, garbage, sewage, gas emissions, noise, radioactive and other hazardous materials, bio-fouling, chemicals, other dangerous cargoes, and others.

Then, for a specific case above, $\mathrm{E}(\mathrm{TOT})$ and $\mathrm{E}_{\mathrm{RCO}}(\mathrm{TOT})$ can be redefined as the expected annual total costs associated with its environmental consequences, before and after the application of a specific RCO for reducing the risk of such consequences (respectively). For instance, one may contemplate a measure to mitigate SOx emissions, a measure to reduce recycling residues, and so on. It is of course assumed that there is a way to compute these costs, but this is another matter. The approach of the United Kingdom to environmental risk criteria ${ }^{10}$ is perhaps the most relevant here, addressing not only oil pollution, but the broader spectrum of environmental consequences.

\footnotetext{
${ }^{7}$ In FSA, CAF is differentiated between GCAF and NCAF, G for Gross and $\mathrm{N}$ for Net. In case NCAF is used, $\Delta \mathrm{C}$ is replaced by $\Delta \mathrm{C}-\Delta \mathrm{B}$, where $\Delta \mathrm{B}$ accounts for expected benefits due to the RCO (other than lives saved).

${ }^{8}$ This condition is if the GCAF criterion is used. For NCAF, the condition becomes $\Delta \mathrm{K}<$ $\Delta \mathrm{E}(\mathrm{TOT})+\mathrm{VHL} * \Delta \mathrm{R}+\Delta \mathrm{B}$.

${ }^{9}$ See IMO document MSC82/INF.3 (submitted by Greece) for a discussion on possible pitfalls on the use of ratio tests in this step of the FSA.

${ }^{10}$ (see doc. MEPC 57/17 and also report on their web site http://www.mcga.gov.uk/c4mca/final_report_rp_591-2.pdf ).
} 


\section{Conclusions}

We have proposed an approach for Steps 3 and 4 of the FSA that takes on board environmental risk evaluation criteria within IMO's guidelines for Formal Safety Assessment (FSA). Such criteria are relevant for evaluating on a cost-benefit basis Risk Control Options (RCOs) for reducing oil spill pollution risk. The proposed approach may be useful in extending FSA to cover environmental risk evaluation criteria, and combines such criteria with criteria already in use in FSA. The approach is readily implementable as long as data for the model described is readily available. So a possible next step is to look at available data and put some numbers behind the theory.

In addition to issues 1 and 3 of the list of open issues (Severity Index, F-N curves, etc), other issues still to be looked at include the issues of RCO interdependencies, which can be tackled the same way as currently in FSA.

\section{Acknowledgments}

Much like several other papers on FSA, this paper is the outgrowth of non-sponsored research by the author and his colleagues at the Laboratory for Maritime Transport at NTUA (www.martrans.org). A version of this paper, containing the methodological material presented herein, has been circulated to the IMO/MEPC correspondence group (CG) on environmental risk evaluation criteria, of which the author is the coordinator. Sincere thanks are due to the members of the CG for their contributions and to the IMO/MEPC secretariat for its cooperation throughout the process. Comments by Jack Devanney, Dagmar Schmidt Etkin and Panos Zachariadis on earlier versions of this paper are also appreciated.

\section{References}

Etkin, D.S., 1999, "Estimating Cleanup Costs for Oil Spills", Proceedings, International Oil Spill Conference, American Petroleum Institute, Washington, DC..

Etkin, D.S., 2000, "Worldwide Analysis of Marine Oil Spill Cleanup Cost Factors", Arctic and Marine Oil Spill Program Technical Seminar, June.

Kontovas C.A., H. N. Psaraftis, 2006, "Assessing Environmental Risk: Is a single figure realistic as an estimate for the cost of averting one tonne of spilled oil?", National Technical University of Athens, Working paper NTUA-MT-06-01, February. Available at www.martrans.org.

Skjong, R., E. Vanem, Ø. Endresen, 2005, "Risk Evaluation Criteria", SAFEDOR-D4.5.2-2005-10-21-DNV, October. Available at www.safedor.org.

White, I.C., F. Molloy, 2003, "Factors that Determine the Cost of Oil Spills", International Oil Spill Conference 2003, Vancouver, Canada, April. 


\section{Related bibliography (sample)}

Etkin, D.S. 2004, "Modeling oil spill response and damage costs," Proceedings of 5th Biennial Freshwater Spills Symposium.

Etkin, D.S., 2005, "Development of an oil spill response cost-effectiveness analytical tool," Proceedings of 28th Arctic and Marine Oilspill Program Technical Seminar: 889-922.

Etkin, D.S., D. French McCay, and J. Rowe. 2006, "Modeling to evaluate effectiveness of variations in spill response strategy," Proceedings of 29th Arctic and Marine Oilspill Program Technical Seminar: 879 - 892.

Kontovas, C.A., 2005, "Formal Safety Assessment: Critical Review and Future Role," Diploma Thesis, National Technical University of Athens, July (available at www.martrans.org).

Kontovas, C. A., H.N. Psaraftis, and P. Zachariadis, 2007, "The Two C's of the Risk Based Approach to Goal-Based Standards: Challenges and Caveats," International Symposium on Maritime Safety, Security and Environmental Protection (SSE07), Athens, Greece, September.

Kontovas, C. A., H.N. Psaraftis, and P. Zachariadis, 2007, "Improvements in FSA Necessary for Risk-Based GBS," PRADS 2007 Conference, Houston, USA, October.

Zachariadis, P., H.N.Psaraftis, and C.A. Kontovas, 2007, "Risk Based Rulemaking \& Design - Proceed with Caution," RINA conference on Developments in Classification and International Regulations, London, UK, January.

Zagoraios, G. ,2008, “A Study of Oil Spill Response Cost in Greece,” Diploma Thesis, National Technical University of Athens (in Greek). 


\section{ANNEX A}

\section{ANALYTICAL METHODOLOGY}

This Annex presents the approach presented in the main body of this paper in more detail. The focus is on oil spill pollution.

\section{RCOs for Reducing the Risk of Oil Spill Pollution}

To create a useful and practical framework for evaluating oil pollution risk, and, perhaps more important, how said risk can be changed by applying a specific RCO, conceptually we assume that the oil spill generation process is governed by a number of independent random processes. The first random process generates spills time-wise on a global basis. The second random process determines the geographical location of the spill. The third random process determines the volume of the spill. A fourth process may determine the type of oil. More random processes may deal with prevailing weather conditions at the time of the spill, and so on.

First for the status quo, let us define the following parameters.

$\lambda$ : Rate of occurrence (frequency) of oil spills, worldwide (in spills/yr). Assuming that spills occur independently of one other and that there is no memory in the spill generation process, one can safely assume that a Poisson process is the process behind oil spill generation worldwide.

$\mathrm{P}_{\mathrm{i}}$ : Conditional probability that spill occurs in location $\mathrm{I}(\mathrm{i}=1, . ., \mathrm{I})$, given a spill occurs. Here we assume that the world is divided into I major locations, that is, Europe, North America, etc. The way the world is divided into such locations, the size of each location, and other parameters is a user input, and depends on the scenario to be analyzed.

$f_{v}(v)$ : Probability density function (PDF) of the volume of a spill $(0<v<\infty)$.

$\mathrm{p}_{\mathrm{j}}$ : Probability of oil type $\mathrm{j}(\mathrm{j}=1, \ldots, \mathrm{J})$. This is the conditional probability of a spill being of oil type $\mathrm{j}$, given a spill occurs. $\mathrm{J}$ is the number of possible oil types, that is, gasoline, diesel oil, crude, etc.

Note that the approach can be generalized for the case each oil type and/or location has its own spill volume PDF, or even for the case where each location has a different distribution of oil types. Note also that if $\mathrm{I}=\mathrm{J}=1$ (one type of oil: all petroleum products, one location: the world), the approach simplifies considerably, but we may lose some information that is useful (we may also consider the intermediate case $\mathrm{J}=1$, $\mathrm{I}>1$, or vice versa).

An oil spill will have economic consequences, which are assumed to be quantified as follows.

$\mathrm{D}_{\mathrm{ij}}(\mathrm{v})$ : damage cost function $=$ expected economic damage if spill of type $\mathrm{j}$ hits area $\mathrm{i}$ with a volume of $\mathrm{v}$. This function is generally a non-linear function of $v$. The expectation is taken over the possible ranges of all other random variables that are not explicitly considered here, for instance, weather conditions when spill occurs, etc.

$\mathrm{C}_{\mathrm{ij}}(\mathrm{v})$ : cleanup cost function $=$ expected cost of cleaning up a spill of type $\mathrm{j}$ that hits area $\mathrm{i}$ and has a volume of $\mathrm{v}$. This function depends on the response level and 
response tactics, which here we assume to be a constant. Addressing oil spill response alternatives is outside the scope of this paper.

$\mathrm{TOT}_{\mathrm{ij}}(\mathrm{v})=$ expected total cost of a spill of type $\mathrm{j}$ that hits area $\mathrm{i}$ and has a volume of $\mathrm{v}$ $=\mathrm{D}_{\mathrm{ij}}(\mathrm{v})+\mathrm{C}_{\mathrm{ij}}(\mathrm{v})$.

It is assumed that all of the above cost functions are known, that is, can be calculated from available data (ITOPF, IOPC funds, national data, etc). ${ }^{11}$ This is an assumption that is probably easier stated than implemented, as available data may be of nonuniform or dubious quality. But if such data is not available, it will be very difficult to conduct a meaningful cost-benefit assessment.

Based on the above inputs, the following can be calculated:

$\lambda p_{j}=$ worldwide frequency of spills of type $j$

$\lambda P_{i}=$ frequency of spills in area $i$

$\lambda p_{j} P_{i}=$ frequency of spills of type $j$ in area $i$

$\mathrm{E}(\mathrm{v})=\int_{\mathrm{V}} \mathrm{f}_{\mathrm{v}}(\mathrm{v}) \mathrm{dv}=$ expected volume of a spill worldwide ${ }^{12}$.

$E\left(D_{i j}\right)=\int D_{i j}(v) f_{v}(v) d v=$ expected economic damage of a spill of type $j$ in area $i$.

$E\left(T T_{i j}\right)=\int T T_{i j}(v) f_{v}(v) d v=$ expected total cost of a spill of type $j$ in area $i$.

$\lambda E\left(D_{i j}\right)=$ expected annual economic damage of all spills of type $j$ in area $i$.

$\lambda E\left(\right.$ TOT $\left._{\mathrm{ij}}\right)=$ expected annual total cost of all spills of type $\mathrm{j}$ in area $i$.

$\mathrm{E}(\mathrm{D})=\lambda \sum \sum \mathrm{p}_{\mathrm{j}} \mathrm{P}_{\mathrm{i}} \mathrm{E}\left(\mathrm{D}_{\mathrm{ij}}\right)=$ expected annual economic damage of all spills worldwide.

$\mathrm{E}(\mathrm{TOT})=\lambda \sum \sum \mathrm{p}_{\mathrm{j}} \mathrm{P}_{\mathrm{i}} \mathrm{E}\left(\mathrm{TOT}_{\mathrm{ij}}\right)=$ expected annual total cost of all spills worldwide.

An RCO that reduces the risk of oil pollution may generally do any or all of the following:

1) It may change the spill frequency from $\lambda$ to $\mu$ (presumably $\mu \leq \lambda$ ).

2) It may change the PDF of the spill volume $f_{v}(v)$ to $g_{v}(v)$ (presumably it will shift it to the left, ie less oil is likely to be spilled because of it, and the expected spill volume will be reduced- see Figure 1 below).

3) It may also impact probabilities $\mathrm{p}_{\mathrm{j}}$ and $\mathrm{P}_{\mathrm{i}}$, if applied non-uniformly.

\footnotetext{
${ }^{11} \mathrm{CG}$ members are asked to identify sources and (if possible) provide relevant data.

${ }^{12}$ All integrals are from zero to infinity. $\int f_{V}(v) d v=1$. $E($.$) is the expectation operator, in a$ probabilistic sense.
} 


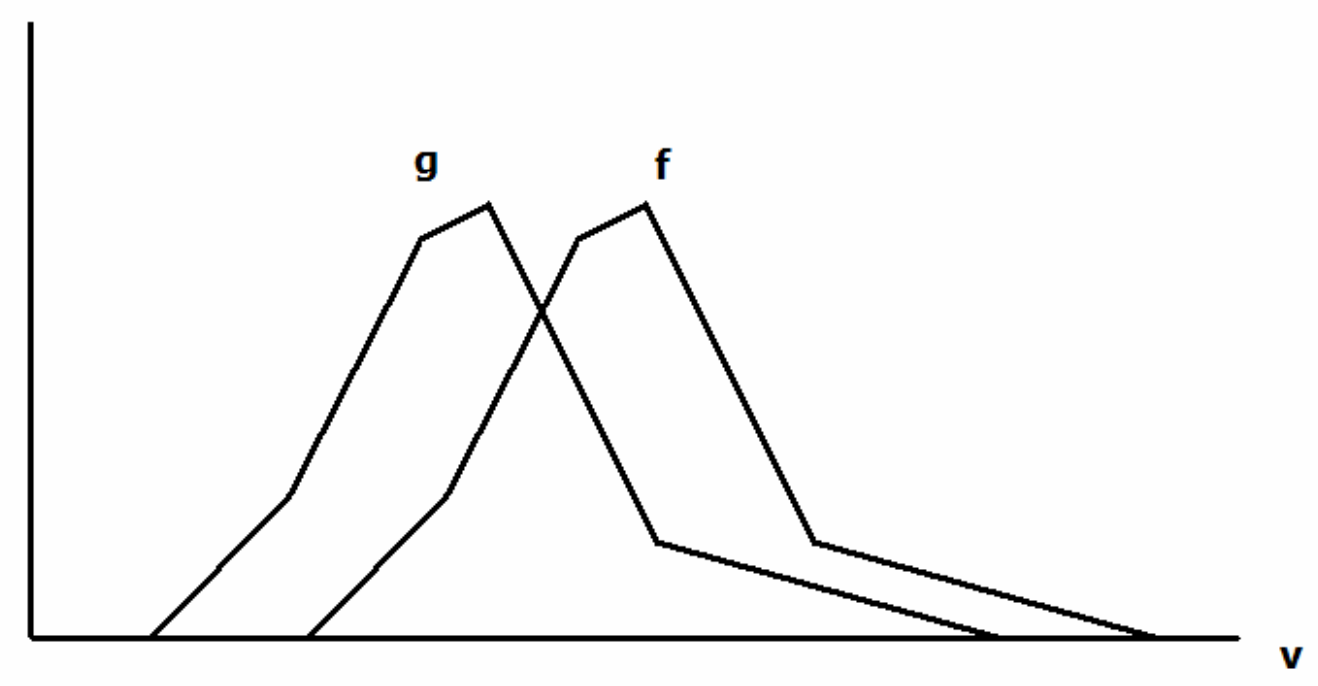

\section{Fig. 1: Shift of the spill volume PDF to the left because of an RCO}

Important assumption: We assume that we have a way of inferring the new frequencies, PDFs and probabilities as defined above. This is not necessarily easy, but we assume it can be done, with the use of probabilistic modelling, Bayesian analysis and/or the help of expert opinion. This is not very different from what is currently done in FSA to quantify the impact of a specific RCO on fatality risk reduction. If assumptions and/or expert opinion are necessary to do so for our case, the same already happens in any FSA.

So the new situation, with the specific RCO under consideration implemented, and for the specific way that this is carried out, will look as follows:

$\mu$ : new rate of occurrence (frequency) of oil spills, worldwide (spills/yr). This is again a Poisson process and $\mu$ is generally a function of the specific RCO. One would expect that $\mu=\lambda$ if the RCO concerns only measures to mitigate the impact of the spill (eg, smaller cargo tanks). However, if the RCO concerns measures to prevent the spill (eg, twin screws, VTMIS, etc), then one would expect that $\mu<\lambda$.

$\mathrm{Q}_{\mathrm{i}}$ : Probability that spill occurs in location $\mathrm{i}(\mathrm{i}=1, . ., \mathrm{I})$. That also may be a function of the RCO, as the introduction of the RCO may not have uniform impact geographically (example: introduce a VTMIS in the Aegean).

$\mathrm{g}_{\mathrm{v}}(\mathrm{v})$ : New PDF of volume of spill $(0<\mathrm{v}<\infty)$. This will also be a function of the specific RCO.

$\mathrm{q}_{\mathrm{j}}$ : Probability of oil type $\mathrm{j}(\mathrm{j}=1, . ., \mathrm{J})$. This may be a function of the RCO, as the RCO may have non uniform impact on certain types of oil (example: introduce an RCO for gasoline tankers).

$D_{i j}(v)$ : damage cost function $=$ expected economic damage if spill of type $\mathrm{j}$ hits area $\mathrm{i}$ with a volume of v. (non-linear function of v). This is assumed the same as before, as the RCO will do nothing if the same volume of $\mathrm{v}$ is spilled.

$\mathrm{C}_{\mathrm{ij}}(\mathrm{v})$ : cleanup cost function $=$ expected cost of cleaning up a spill of type $\mathrm{j}$ that hits area $\mathrm{i}$ and has a volume of $\mathrm{v}$. This function depends on the response level and 
response tactics, which here we assume to be a constant. This is also assumed same as before.

$\operatorname{TOT}_{\mathrm{ij}}(\mathrm{v})=$ expected total cost of a spill of type $\mathrm{j}$ that hits area $\mathrm{i}$ and has a volume of $\mathrm{v}$ $=\mathrm{D}_{\mathrm{ij}}(\mathrm{v})+\mathrm{C}_{\mathrm{ij}}(\mathrm{v})$ - same as before.

In the same spirit,

$\mu \mathrm{q}_{\mathrm{j}}=$ new frequency of spills of type $\mathrm{j}$

$\mu \mathrm{Q}_{\mathrm{i}}=$ new frequency of spills in area $\mathrm{i}$

$\mu \mathrm{q}_{j} \mathrm{Q}_{\mathrm{i}}=$ new frequency of spills of type $\mathrm{j}$ in area $\mathrm{i}$

$\mathrm{E}_{\mathrm{RCO}}(\mathrm{v})=\int_{\mathrm{v}} \mathrm{g}_{\mathrm{v}}(\mathrm{v}) \mathrm{dv}=$ new expected volume of all spills worldwide.

$E_{R C O}\left(D_{i j}\right)=\int D_{i j}(v) g_{v}(v) d v=$ new expected economic damage of a spill of type $j$ in area $\mathrm{i}$.

$E_{R C O}\left(T T_{i j}\right)=\int T T_{i j}(v) g_{v}(v) d v=$ new expected total cost of a spill of type $j$ in area i.

$\mu E_{R C O}\left(D_{i j}\right)=$ new expected annual economic damage of all spills of type $j$ in area $i$.

$\mu \mathrm{E}_{\mathrm{RCO}}\left(\mathrm{TOT}_{\mathrm{ij}}\right)=$ new expected annual total cost of all spills of type $\mathrm{j}$ in area $\mathrm{i}$.

$\mathrm{E}_{\mathrm{RCO}}(\mathrm{D})=\mu \sum \sum \mathrm{q}_{\mathrm{j}} \mathrm{Q}_{\mathrm{i}} \mathrm{E}_{\mathrm{RCO}}\left(\mathrm{D}_{\mathrm{ij}}\right)=$ new expected annual economic damage of all spills worldwide.

$\mathrm{E}_{\mathrm{RCO}}(\mathrm{TOT})=\mu \sum \sum \mathrm{q}_{\mathrm{j}} \mathrm{Q}_{\mathrm{i}} \mathrm{E}_{\mathrm{RCO}}\left(\mathrm{TOT}_{\mathrm{ij}}\right)=$ new expected annual total cost of all spills worldwide.

\section{Cost benefit assessment}

With the above in mind, we can calculate the expected cost differentials between the status quo and the situation in which the RCO under consideration is applied.

$\Delta \mathrm{E}(\mathrm{D})=\mathrm{E}(\mathrm{D})-\mathrm{E}_{\mathrm{RCO}}(\mathrm{D})$, expected economic damage averted due to the global application of the RCO, and

$\Delta \mathrm{E}(\mathrm{TOT})=\mathrm{E}(\mathrm{TOT})-\mathrm{E}_{\mathrm{RCO}}(\mathrm{TOT})$, total expected cost averted due to the global application of the RCO.

Notes:

1) The operators $\mathrm{E}$ and $\Delta$ can be interchanged, ie $\Delta \mathrm{E}(\mathrm{TOT})=\mathrm{E}(\Delta(\mathrm{TOT}))$.

2) The stakeholders who are the beneficiaries of money savings $\Delta E(D)$ and $\Delta \mathrm{E}$ (TOT) are not the same, and they are not the same with those who incur $\operatorname{cost} \Delta \mathrm{K}^{13}$ to reduce environmental risk! We do not deal with this issue here (distribution of costs and benefits), assuming that our 'black box' is "society". But it is an issue that needs to be addressed, otherwise those who pay but do not receive benefits will react.

Still, we can say that

- The specific RCO under consideration is cost-effective globally if its total cost $\Delta \mathrm{K}<\Delta \mathrm{E}(\mathrm{TOT})$, otherwise it is not.

Again, $\Delta \mathrm{K}$ is an equivalent annualized value. 
- Among alternative RCOs that pass this criterion, the one that achieves the highest positive difference $\{\Delta \mathrm{E}(\mathrm{TOT})-\Delta \mathrm{K}\}$ is preferable.

As shown in the main body of the paper, this approach can be extended to combine environmental risk and fatality risk. This need not be repeated here.

Let us know examine some special cases.

\section{Special cases}

One special case is if we assume that $\mu=\lambda$ (ie, the RCO concerns post-accident measures only, not prevention) $\mathrm{q}_{j}=\mathrm{p}_{\mathrm{j}}$ (ie, RCO is neutral to the type of oil)

$\mathrm{Q}_{\mathrm{i}}=\mathrm{P}_{\mathrm{i}}$ (ie, RCO is neutral to the spill location)

Then

$\Delta \mathrm{E}(\mathrm{TOT})=\lambda \sum \sum \mathrm{p}_{\mathrm{j}} \mathrm{P}_{\mathrm{i}} \int\left[\mathrm{D}_{\mathrm{ij}}(\mathrm{v})+\mathrm{C}_{\mathrm{ij}}(\mathrm{v})\right] \cdot\left[\mathrm{f}_{\mathrm{v}}(\mathrm{v})-\mathrm{g}_{\mathrm{v}}(\mathrm{v})\right] \mathrm{dv}$

Then the $R C O$ is cost-effective if $\Delta K<\Delta E(T O T)$

Even more special case is the linearity case:

Assume both functions D and C are linear in $\mathrm{v}$, ie assume $\operatorname{TOT}_{\mathrm{ij}}(\mathrm{v})=\mathrm{b}_{\mathrm{ij}} \mathrm{v}$. Then

$\Delta \mathrm{E}(\mathrm{TOT})=\lambda \sum \sum \mathrm{p}_{\mathrm{j}} \mathrm{P}_{\mathrm{i}} \mathrm{b}_{\mathrm{ij}} \int \mathrm{v}\left[\mathrm{f}_{\mathrm{v}}(\mathrm{v})-\mathrm{g}_{\mathrm{v}}(\mathrm{v})\right] \mathrm{dv}$

Or $\Delta \mathrm{E}(\mathrm{TOT})=\mathrm{A} \Delta \mathrm{E}(\mathrm{V})$,

where $\mathrm{A}=\lambda \sum \sum \mathrm{p}_{\mathrm{j}} \mathrm{P}_{\mathrm{i}} \mathrm{b}_{\mathrm{ij}}, \mathrm{a}$ constant, and

and $\Delta \mathrm{E}(\mathrm{V})=\mathrm{E}(\mathrm{v})-\mathrm{E}_{\mathrm{RCO}}(\mathrm{v})$, the difference in expected volume of one spill between the status quo (without RCO) and the RCO implemented.

In this case, the RCO is cost-effective if

$\Delta \mathrm{K}<\mathrm{A} \Delta \mathrm{E}(\mathrm{V})$, or

$\Delta \mathrm{K} / \Delta \mathrm{E}(\mathrm{V})<\mathrm{A}$

In fact, an even more special case is this:

If for all $\mathrm{i}$ and $\mathrm{j}, \mathrm{b}_{\mathrm{ij}}=\mathrm{B}=$ constant (average unit spill cost in dollars/tonne), then (since $\sum \sum \mathrm{p}_{\mathrm{j}} \mathrm{P}_{\mathrm{i}}=1$ )

$\mathrm{A}=\lambda \mathrm{B}$, and the $\mathrm{RCO}$ is cost-effective if 
$\Delta \mathrm{K} / \Delta \mathrm{E}(\mathrm{V})<\lambda \mathrm{B}$, or

$\Delta \mathrm{K} /[\lambda \Delta \mathrm{E}(\mathrm{V})]<\mathrm{B}$

The denominator is the difference of expected total volume spilled in one year, let's name it $\Delta \mathrm{E}_{\text {year }}(\mathrm{V})$.

Then the criterion is:

$\Delta \mathbf{K} / \Delta \mathbf{E}_{\text {year }}(\mathbf{V})<\mathbf{B}$

That is, the RCO is cost-effective if its total implementation cost $\Delta \mathrm{K}$, divided by the expected total spill volume it will avert in one year, is less than this constant B.

One can also convert this into an individual ship basis: If the RCO is to be applied to $\mathrm{N}$ ships, and $\Delta \mathrm{K} / \mathrm{N}=\delta \mathrm{k}$ (cost per ship), then $\mathrm{RCO}$ is cost-effective if

$\delta \mathrm{k} /\left(\Delta \mathrm{E}_{\text {year }}(\mathrm{V}) / \mathrm{N}\right)<\mathrm{B}$.

The numerator is the per ship cost of implementing the RCO (on an annual basis) and the denominator is the per ship difference of expected total volume spilled in one year. If the ratio of this two is less than $\mathrm{B}$, the RCO is cost-effective.

Note: For this special case, constant $B$ is the equivalent to what project SAFEDOR names CATS, but it is calculated by a different method. So in a sense the approach that is suggested herein is a generalization of CATS.

How this can be used: If for any reason ${ }^{14}$ we want to assume linear cost functions of spill volume, the way to do it is this: Calculate the coefficients $a_{i j}$, and then the constants $\mathrm{A}$ and $\mathrm{B}$, as shown above.

If the cost functions are non-linear, we can do these calculations again, assuming the form of non-linear function is known. Available data suggest significant nonlinearities.

\section{More special cases}

Let us now assume that

$\mu<\lambda$ (the only difference)

$\mathrm{g}_{\mathrm{v}}(\mathrm{v})=\mathrm{f}_{\mathrm{v}}(\mathrm{v})$

$\mathrm{q}_{\mathrm{j}}=\mathrm{p}_{\mathrm{j}}$ (RCO is neutral to the type of oil)

$\mathrm{Q}_{\mathrm{i}}=\mathrm{P}_{\mathrm{i}}$ (RCO is neutral to the spill location)

This is the case where RCO only reduces frequency, with same spill volume distribution: That is, the RCO does not concern the ship itself, but measures that can be taken to reduce the probability of spills to occur: a VTMIS system, for instance. Ships remain exactly as they are.

\footnotetext{
${ }^{14}$ Possible reasons: simplicity, political considerations, or the fact that any volume of oil spilled should be treated the same.
} 
Even the RCO of "twin screw for tankers", with no other change in the design of tankers, would do the same thing: reduce spill frequency, but leave PDF of spill volume unchanged. Of course, if (as expected) twin screws involve changes in tanker design, then the PDF of spill volume may also change.

Then

$\Delta \mathrm{E}(\mathrm{TOT})=\int\left\{\sum \sum\left[\mathrm{TOT}_{\mathrm{ij}}(\mathrm{v})\right]\left\{\lambda \mathrm{p}_{\mathrm{j}} \mathrm{P}_{\mathrm{i}} \mathrm{g}_{\mathrm{v}}(\mathrm{v})-\mu \mathrm{q}_{\mathrm{j}} \mathrm{Q}_{\mathrm{i}} \mathrm{f}_{\mathrm{v}}(\mathrm{v})\right\} \mathrm{dv}=\right.$

$=(\lambda-\mu) \int\left\{\sum \sum\left[\mathrm{TOT}_{\mathrm{ij}}(\mathrm{v})\right] \mathrm{p}_{\mathrm{j}} \mathrm{P}_{\mathrm{i}} \mathrm{f}_{\mathrm{v}}(\mathrm{v}) \mathrm{dv}=\right.$

For the linear case, $\mathrm{TOT}_{\mathrm{ij}}(\mathrm{v})=\mathrm{b}_{\mathrm{ij}} \mathrm{v}$, and

$\Delta \mathrm{E}(\mathrm{TOT})=(\lambda-\mu) \int\left\{\sum \sum \mathrm{p}_{\mathrm{j}} \mathrm{P}_{\mathrm{i}} \mathrm{b}_{\mathrm{ij}} \mathrm{v} \mathrm{f}_{\mathrm{v}}(\mathrm{v}) \mathrm{dv}=\right.$

$=A(\lambda-\mu) E(v)$, with $A=\sum \sum p_{j} P_{i} b_{i j}$

Here the expected benefits are proportional to the reduction in spill frequency, which is logical.

\section{Optimizing RCO resources}

What is described in this section should not necessarily belong to an FSA. But the section may provide some interesting insights as regards cost-benefit assessment, not only for environmental criteria, but also for the "standard" FSA criteria.

In a cost-benefit context, we try to address a question that is different from those typically asked in Step 4 of FSA, but is related nonetheless: Given we have a limited total budget of $\mathrm{C}$, which ship type or types provide the best way to apply a specific $\mathrm{RCO}$ ? "Best" may mean maximizing $\triangle \mathrm{E}(\mathrm{TOT})$ for a given budget of $\mathrm{C}$ that cannot be exceeded.

Let's assume that the RCO in question concerns only ship-related measures that can be applied to the existing fleet of ships, consisting of $\mathrm{N}$ distinct types of ships, or combinations of ship types and size brackets. Let $c_{n}$ be the total cost of implementing this RCO on ship category $n$ (all ships of that category), for $n=1, . . \mathrm{N}^{15}$.

Define binary decision variable $\mathrm{x}_{\mathrm{n}}=1$ if this RCO is implemented on ship category $\mathrm{n}$ (all of them), and 0 otherwise.

Then the total (annualized) cost of implementation of this RCO will be $\sum c_{n} x_{n}$.

What will be the expected benefit of implementing this RCO?

If it is implemented only on ship category $\mathrm{n}$, then we will have an expected benefit of $\Delta \mathrm{E}(\mathrm{TOT})_{\mathrm{n}}$, provided of course we can calculate it.

\footnotetext{
${ }^{15} \mathrm{C}$ and all $\mathrm{c}_{\mathrm{n}}$ 's are on an equivalent annualized basis.
} 
Then the total expected benefit will be $\sum \Delta \mathrm{E}(\mathrm{TOT})_{\mathrm{n}} \mathrm{x}_{\mathrm{n}}$.

The assumption here is that this is an additive benefit function. This is a reasonable assumption if expected benefits attributed to different ship categories are independent of one another.

Then for a fixed total budget $\mathrm{C}$ that cannot be exceeded, we can formulate this as an optimization problem, as follows (decision variables are the $\mathrm{x}_{\mathrm{n}}$ 's):

Maximize $\sum \Delta \mathrm{E}(\mathrm{TOT})_{\mathrm{n}} \mathrm{x}_{\mathrm{n}}$

Subject to $\sum \mathrm{c}_{\mathrm{n}} \mathrm{x}_{\mathrm{n}} \leq \mathrm{C}$

$\mathrm{x}_{\mathrm{n}} \in\{0,1\}$

Obviously this problem has a trivial solution of $x_{n}=0$ for every $\mathrm{n}$ if $\mathrm{C}$ is less than the smallest of $c_{n}$ 's, and a trivial solution of $x_{n}=1$ for every $n$ if $C \geq \sum c_{n}$. Therefore the problem is only interesting if $\mathrm{C}<\sum \mathrm{c}_{\mathrm{n}}$.

The above is a well known integer programming problem, known as the 'knapsack' problem, which can be solved exactly by dynamic programming. It can also be solved heuristically by the so-called 'greedy' algorithm, which works as follows:

1. Rank-order all ship categories by descending order of $\left\{\Delta \mathrm{E}(\mathrm{TOT})_{\mathrm{n}} / \mathrm{c}_{\mathrm{n}}\right\}$ ratios (expected benefit per unit cost).

2. First apply RCO to ship category that has the highest ratio of $\left\{\Delta \mathrm{E}(\mathrm{TOT})_{\mathrm{n}} / \mathrm{c}_{\mathrm{n}}\right\}$.

3. If the remaining budget allows it, apply RCO to ship category with the next highest ratio $\left\{\Delta \mathrm{E}(\mathrm{TOT})_{\mathrm{n}} / \mathrm{c}_{\mathrm{n}}\right\}$. If it does not, move to category with the next highest ratio.

4. Repeat until overall budget is exhausted.

The analogy of the $\left\{\Delta \mathrm{E}(\mathrm{TOT})_{\mathrm{n}} / \mathrm{c}_{\mathrm{n}}\right\}$ ratio to something that resembles $\mathrm{CAF}$ (or in fact CATS) can be seen, even though no linearity in spill volume is assumed. Note however that the greedy algorithm is only a heuristic; it does not necessarily produce an optimal solution, as seen in the hypothetical example below.

Assume $\mathrm{N}=4, \mathrm{C}=$ available budget $=5$.

Assume also the following data (cost, benefit and budget units are in \$billion/yr):

\begin{tabular}{|l|c|c|c|}
\hline $\mathrm{n}$ & $\Delta \mathrm{E}(\mathrm{TOT})_{\mathrm{n}}$ & $\mathrm{c}_{\mathrm{n}}$ & $\Delta \mathrm{E}(\mathrm{TOT})_{\mathrm{n}} / \mathrm{c}_{\mathrm{n}}$ \\
\hline 1 & 15 & 2 & 7.5 \\
\hline 2 & 21 & 3 & 7 \\
\hline 3 & 32 & 4 & 8 \\
\hline 4 & 2 & 1 & 2 \\
\hline
\end{tabular}

Here the greedy solution is to first pick ship category 3, as the one achieving the highest expected benefit/cost ratio $(=8)$. This uses 4 units of our available budget. But then the only other ship category that can be picked within the remaining budget $(=1)$ is category 4 . This produces a total expected benefit of $32+2=34$. 
The greedy solution is not optimal. The optimal solution is to choose ship categories 1 and 2 , with a total expected benefit of $15+21=36$.

Solving this problem may help policy makers identify which ship categories are more cost-effective to implement a specific RCO if there is a limit in the allowable budget. 